Es ist darauf zu achten, dass man Luftblasen, die sich nach dem Einlegen im Wasser gebildet haben, vor dem Andrücken an die Porzellanschale möglichst vertheilt.

Die fertig geformte Schale wird nun entweder an der Luft oder besser und rascher in einem allmählich anzuheizenden Luftbade getrocknet. Die Schalen werden klingend hart, halten sehr starke Hitze aus und sollen sich überhaupt in jeder Hinsicht bewähren.

\title{
Zum Entfernen kleiner Reste von Niederschlägen aus Glasge.
} fässen, an deren Wandungen sie fest haften, benutzt A lexander Müller*) an Stelle der Federn oder der mit einem Stückchen Kautschukschlauch überzogenen Glasstäbe kleine, zungenförmig geschnittene Stückchen von rulkanisirtem Kautschuk, in deren hinteres Ende er einen hinreichend steifen Metalldraht einbohrt. Das Instrument hat namentlich den Vorzug, dass man durch geeignete Biegung des Drahtes auch solche Theile der Gefässwandung zu erreichen vermag, an welche man mit einer Feder oder einem Glasstab nicht gelangen kann.

Bei der Aufbewahrung von Sauerstoffgas in Zinkgasometern empfiehlt $J$ ulius Löw $\mathrm{e}^{* *}$ ) als Absperrfiüssigkeit statt reinen Wassers Kalkwasser zu verwenden. Man hat dabei den Vortheil, dass Kohlensäure oder auch andere Säuren, die aus der Luft des Laboratoriums in das $\Delta$ bsperrwasser gelangen, sofort neutralisirt werden und vermeidet so jede Verunreinigung des Sauerstoffs durch Kohlensäure oder Wasserstolit, der sich aus dem Zink des Gasometers mit dem sauren Wasser entwickeln könnite $\left.{ }^{* * *}\right)$.

Der Verfasser hängt in das Wasser des Gasometers einen Leinwandbeutel mit gelöschtem Kalk, den er von Zeit zu Zeit erneuert und erhält auf diese Weise das Kalkwasser stets gesättigt. Die Vorzüge dieser Aufbewahrung machen sich namentlich geltend, wenn man den Sanerstofi bei Elementaranalysen benutzt.

*) Iandwirthschaftliche Versuchsstationen $\mathbf{2 7}, 339$.

*) Ann. d. Phys. und Chemie [N. F.] 18, 176.

***) L. Pfaundier hat vor kurzem beobachtet, dass längere Zeit in einem Zinkgasometer aufbewahrter Sauerstoff in Berührung mit einem brennenden Körper explodirte und vermuthet, dass der Grund hierfür in einer Beimengung von auf obige Weise entstandenem Wasserstoff zu suchen sei. (Ann. d. Phys. und Chem. [N. F.] 17, 176). 